\title{
Neurophysiology of Philematology and Some Infectious Disease
}

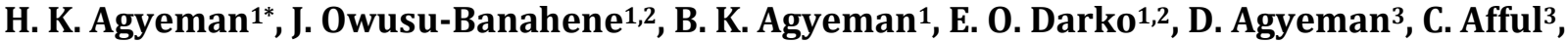 \\ F. Akuffo' ${ }^{1}$ K. M. Bonsu' ${ }^{3}$, S. Inkoom ${ }^{1,2}$, E. T. Glover ${ }^{2}$, D. F. Charles ${ }^{1}$, Wilheliaina Korletey ${ }^{2}$ \\ ${ }^{1}$ Radiation Protection Institute, Ghana Atomic Energy Commission, Accra, Ghana \\ ${ }^{2}$ Graduate School of Nuclear and Allied Sciences, Atomic Campus, Accra, Ghana \\ ${ }^{3}$ University of Ghana, Legon, Ghana \\ Email: *jewel5w@yahoo.com
}

How to cite this paper: Agyeman, H.K., Owusu-Banahene, J., Agyeman, B.K., Darko, E.O., Agyeman, D., Afful, C., Akuffo, F., Bonsu, K.M., Inkoom, S., Glover, E.T., Charles, D.F. and Korletey, W. (2019) Neurophysiology of Philematology and Some Infectious Disease. Advances in Biological Chemistry, 9, 143-155.

https://doi.org/10.4236/abc.2019.94011

Received: March 15, 2019

Accepted: August 18, 2019

Published: August 21, 2019

Copyright $\odot 2019$ by author(s) and Scientific Research Publishing Inc. This work is licensed under the Creative Commons Attribution International License (CC BY 4.0).

http://creativecommons.org/licenses/by/4.0/ (c) (i) Open Access

\begin{abstract}
The scientific studying of kissing is known as Philematology. This originates from the Greek word PHILOS in the ancient days meaning earthly. The study of kissing shows you what kissing means and its place in various cultures. (Lana Citron 2010, a Compendium of Kisses), and the difference between Simple Kiss versus Passionate kiss. In simple kisses only 2 muscles are involved. While in passionate kisses there may be about 23 - 34 facial muscles and 112 postural muscles involved. What you can tell from even the simplest of kisses. From the book I Love You. Now What? During kissing, a lot of chemical reactions take place in the brain and the body as a whole. The part of the brain in which these chemicals are secreted is the pituitary gland, where oxytocin, serotonin and dopamine are secreted. The oxytocin which is also sometimes referred to as the cuddle hormone or the love hormone aids in social bonding. It is produced in the hypothalamus and secreted into the bloodstream by the posterior pituitary gland. Oxytocin is released when the cells are excited. Oxytocin can also be referred to aid carbetocin, manufactured version, Pitocin, alpha-hypophamine and syntocinon. It is a team player in social behaviour and mother-infant bonding. The serotonin which is also known as a "happy hormone" is an important chemical and a neurotransmitter in the human body serves as a hormonal modulator that is serotonin aids regulating an individual kissing pattern, sleeping pattern, aggressive pattern, appetite and digestion pattern, memory and mood pattern and sexual pattern. Finally, the dopamine which is also known as a "happy hormone" is a monoamine neurotransmitter which belongs to the catecholamine family that is made up of epinephrine, norepinephrine and dopamine. This dopamine helps an individual to enjoy the act of kissing.
\end{abstract}




\section{Keywords}

Oxytocin, Serotonin, Simple Kiss, Passionate Kiss, Dopamine

\section{Introduction}

One of the chemicals which are released during kissing is known as dopamine. This dopamine can stimulate some areas of the brain and this makes the individual feel euphoric about the whole act of kissing [1]. Dopamine is also a contributing factor in sharing with other neurotransmitters more especially with oxytocin. The continuous flow of dopamine during kissing from the body, helps to boost our pleasure in the act of kissing. On the other hand, oxytocin which is another chemical in the brain initiates feelings of attachment and affection during kissing. This happens as a result of a good kiss which also releases a chemical known as serotonin [2] in our body which helps in regulating our emotions. This is because a good kisser knows their partners kissing habits. For a good kiss to occur, both partners must be connected naturally and passionately bonded to each other. This ensures how they feel good about how they have been kissed. Normally this experience is not too strong from the kisser. That is the kisser do not come on too strong during the act of kissing.

Kissing is an emotional act, which can be interpreted as a representative of romantic act that can be performed temporary between two individuals. Usually, women enjoy kissing a lot and this makes them feel sexually aroused. Sharing a good kiss at the beginning of a relationship and over time can help maintain a serious and strong connection between partners and this good kiss can also lead to sexual arousement, attachment and bonding. In actual sense, kissing is not difficult at all, because when it is great it can be so amazing. There is a chemistry behind kissing which is usually expressed as the "first date kiss philosophy", which says that there is no wrong or right answer to first date kissing. It emphasizes that on a first date, when your body chemistry tells you or make you feel like kissing your partner or significant other, just go ahead and do it.

Real kissing can be defined as the practice of kissing with an open mouth that allows the partners to suck their lips or move their tongue into their mouth, this is also known as French Kissing. Baby kissing additionally, is another way to comfort babies and to show affection to them, it can either be a forehead kiss, lip kiss or a cheek kiss. Medically, regardless of the duration of a kiss, DNA remains in the mouth for at least one hour after kissing. This is a statement made by an individual medically. On the other hand, when people kiss and they open their eyes, it hinders the pleasure of kissing, that is they experience sensory overload which researchers says, focusing on visual stimuli can cause sensory numbness.

Basically, there are other benefits of kissing, because during kissing, your stress level decreases. According to a study cited on NBC, college students who participated in 15 minutes make out sessions had decreased cortisol levels, the body stress hormone. The study shows that male participant had an increase in 
their oxytocin, the brain feel-good chemical. While female actually saw a decrease. The study also found out that those who participated in kissing felt stronger pair bonds to their partners. Pair bonding is what makes you feel close to the one you love. Moreover, your body is rife with Pheromones, when you kiss someone you love for the first time, your body releases pheromones. These pheromones are natural chemicals that make you to be attracted to each other. Not only this but also, kissing releases burst of adrenaline. That is during kissing, your blood flow is positively impacted, your heart rate increases. This helps to increase your energy levels, giving you a boost of positive vibes.

In addition, your cholesterol improves, this implies that kissing can improve your overall blood lipid level. Research shows that in a study in 2009 edition of the Western Journal of Communication, researchers found out that romantic kissing can actually decrease your serum cholesterol and increase overall relationship satisfaction for couples. Furthermore, your saliva is designed to help you access potential mates. Researchers at Oxford University have found out that kissing is actually designed to help you access a potential mate. All your brain happy chemicals are released during kissing [3]. Naturally, your pupil dilate when you kiss and your eyes are closed, it makes us susceptible to light sensitivity says Marie Clair.

Your saliva typically protects you against bacteria in your partner's saliva. (There will be more bacteria when oral hygiene is poor.) But one bacterium that can be transmitted is MRSA, the serious staph infection. Also, if you have a cold sore, kissing someone can spread the herpes 1 virus. Jun 17, 2016.

It's easy to exchange infectious organisms during a kiss through your saliva. They can find their way from your mouth into your throat and lungs. That is why mono is called the "kissing diseases". You can spread colds and flu by kissing, although cold viruses usually spread by touching a contaminated surface and then your nose "says Dr. Benninger". Your saliva typically protects you against bacteria in your partners saliva. (There will be more bacteria when oral hygiene is poor). One bacteria can be transmitted is MRSA, the staph infection. Also, if you have a cold sore kissing someone can spread the herpes 1 virus. Despite this, there are lots of kissing going on and very few infections "Dr. Benninger".

Kissing causes a chemical reaction in your brain. There are three chemicals that are realized during kissing, these are

Oxytocin (Love Hormone).

Serotonin (Happy Hormone).

Dopamine (Happy Hormone) (Figure 1).

Dopamine is released when you do something that feels good. Like kissing and spending time with someone you are attracted to. It makes you feel giddy and euphoric. In 2013 a study shows that couples who frequently kissed had relationship satisfaction [3].

CHEMICAL FORMULAR OF DOPAMINE 


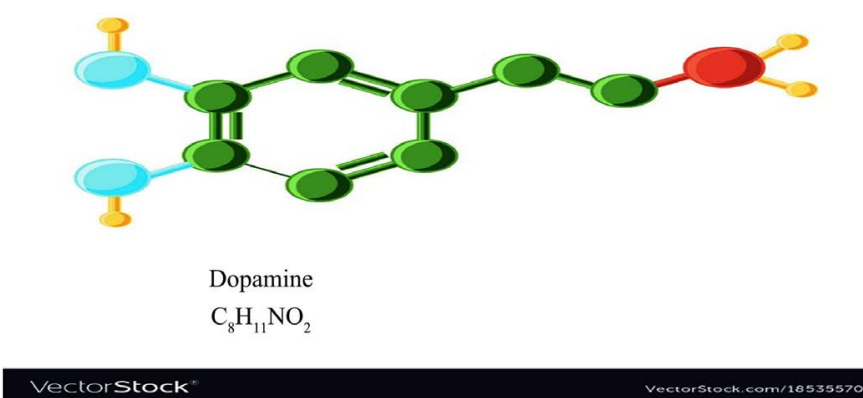

Figure 1. Structural formula of dopamine.

Dopamine is an organic chemical of the catecholamine and phenethylamine families that plays several important roles in the brain and body. It is an amine synthesized by removing a carboxyl group from a molecule of its precursor chemical L-DOPA, which is synthesized in the brain and kidneys.

Metabolism: MAO, COMT.

Biosynthesis: DOPA decarboxylase.

Precursor: Phenylalanine, tyrosine, and L-DOPA.

Source tissues: Substantia nigra; ventral tegmental area; many others.

Receptors: $\mathrm{D}_{1}, \mathrm{D}_{2}, \mathrm{D}_{3}, \mathrm{D}_{4}, \mathrm{D}_{5}$, TAAR1.

Target tissues: System-wide.

CHEMICALS FOUND IN DOPAMINE

- One of the catecholamine NEUROTRANSMITTERS in the brain. Dopamine is derived from TYROSINE and is the precursor to NOREPINEPHRINE and EPINEPHRINE.

- Dopamine is a Catecholamine. The chemical classification of dopamine is Catecholamines.

- Dopamine is a monoamine compound with positive inotropic activity. THE CHEMICAL MAKEUP OF DOPAMIN

A dopamine molecule consists of a catechol structure (a benzene ring with two hydroxyl side groups) with one amine group attached via an ethyl chain. As such, dopamine is the simplest possible catecholamine, a family that also includes the neurotransmitters norepinephrine and epinephrine.

\section{DRUG CLASS OF DOPAMINE}

Dopamine is a precursor to norepinephrine in noradrenergic nerves and is also a neurotransmitter in certain areas of the central nervous system. Dopamine produces positive chronotropic and inotropic effects on the myocardium, resulting in increased heart rate and cardiac contractility (Figure 2).

\section{Serotonin}

Serotonin or 5-hydroxytryptamine is a monoamine neurotransmitter, and is popularly thought to be a contributor to feelings of well-being and happiness. Biochemically, the indoleamine molecule is derived from the amino acid tryptophan. 


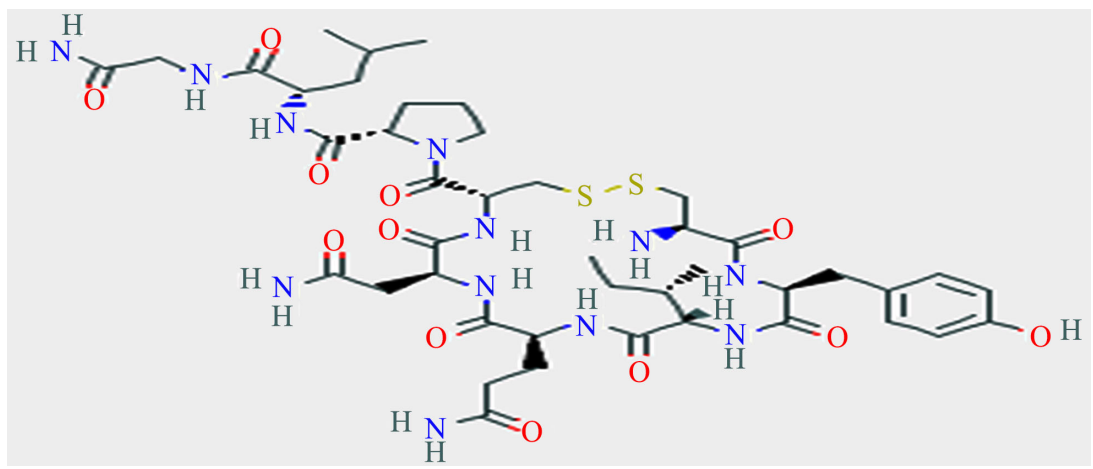

Figure 2. Structural formula of oxytocin (love hormone).

Formula: $\mathrm{C}_{10} \mathrm{H}_{12} \mathrm{~N}_{2} \mathrm{O}$

Molar mass: $176.215 \mathrm{~g} / \mathrm{mol}$

Melting point: $167.7^{\circ} \mathrm{C}$

Boiling point: $416^{\circ} \mathrm{C}$

Metabolism: MAO

IUPAC ID: 3-(2-aminoethyl)-1H-indol-5-ol

Serotonin is also known to be a hormonal modulator that is it aids in the effects of behaviour such as an individual sleeping partners, kissing partners, sexual partners and aggressive partners [4] (Figure 3).

Oxytocin is a hormone secreted by the posterior lobe of the pituitary gland.

It's sometimes known as the "cuddle hormone" or the "love hormone", because it is released when people snuggle up or bond socially. Jun 4, 2015. Oxytocin has long been known as the warm, fuzzy hormone that promotes feelings of love, social bonding and well-being (Jul 22, 2013) [5].

CHEMICAL FORMULAR OF OXYTOCIN

\begin{tabular}{cc}
\hline Chemical Names: & OXYTOCIN; Pitocin; 50-56-6; Ocytocin; Endopituitrina; Orasthin More ... \\
\hline Molecular Formula: & $\mathrm{C}_{43} \mathrm{H}_{66} \mathrm{~N}_{12} \mathrm{O}_{12} \mathrm{~S}_{2}$ \\
Molecular Weight: & $1007.193 \mathrm{~g} / \mathrm{mol}$ \\
InChI Key: & XNOPRXBHLZRZKH-DSZYJQQASA-N \\
\hline
\end{tabular}

\section{WHAT TYPE OF MOLECULE IS OXYTOCIN}

In the pituitary gland, oxytocin is packaged in large, dense-core vesicles, where it is bound to neurophysin I as shown in the inset of the figure; neurophysin is a large peptide fragment of the larger precursor protein molecule from which oxytocin is derived by enzymatic cleavage.

\section{WHAT IS OXYTOCIN MADE OFF}

Oxytocin is a neurotransmitter and a hormone that is produced in the hypothalamus. From there, it is transported to and secreted by the pituitary gland, at the base of the brain. It plays a role in the female reproductive functions, from sexual activity to childbirth and breast feeding. 


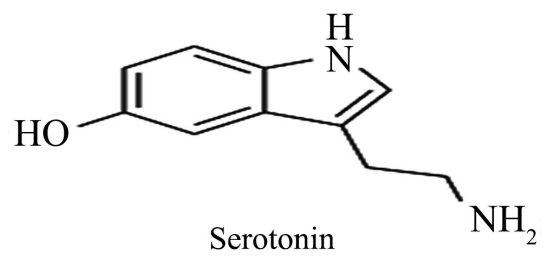

Figure 3. Structural formula of serotonin.

\section{THE COLOR OF OXYTOCIN}

For example, the colour blue is said to increase natural levels of oxytocin, meaning that by wearing a blue shirt, or doing a presentation with the colour blue as your background, you may boost levels of oxytocin amongst your viewers, and therefore their trust of your presentation. Aug 31, 2007.

WHAT PRODUCES OXYTOCIN.

Oxytocin is produced in the hypothalamus and is secreted into the bloodstream by the posterior pituitary gland. Secretion depends on electrical activity of neurons in the hypothalamus-it is released into the blood when these cells are excited.

\section{Types of Kisses}

Basically, there are 40 different types of kisses. But the most common one includes:

Hand kiss.

Cheek kiss.

Butterfly Kiss.

Eskimo Kiss.

Neck Kiss.

Earlobe Kiss.

Angel Kiss.

Kiss on the Forehead.

Hand Kiss (Figure 4).

Meaning of Hand Kiss.

It expresses love and friendship.

Hand Kiss can also denotes a form of greeting (Figure 5).

Another alternative name for Cheek kissing is also as ritual or social kissing.

It can indicate a form of greeting, family relationship and friendship.

Moreover, it can also confer comfort someone or congratulation to someone.

Furthermore, Cheek Kiss is used to indicate romantic interest or sexual interest to someone.

Additionally, it can be used to show respect to someone or a sign of friendship (Aug 3, 2017) (Figure 6).

\section{Meaning of an Angel kiss}

Alternatives names of angel kiss are sometimes known as Macular stains, Birthmarks, and Stork bites. 
They are normally irregular borders which are flat, with red marks or pink marks with irregular borders.

Sometimes, they appear on the eyelids or forehead on the individual and disappear by the age of two years.

Women who pierce their upper lips and put small jewels on their upper lips is also call angel kiss piercing (Figure 7).

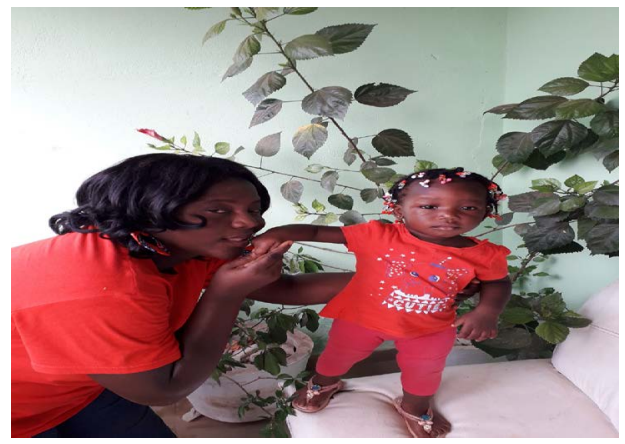

Figure 4. Picture of hand kissing.

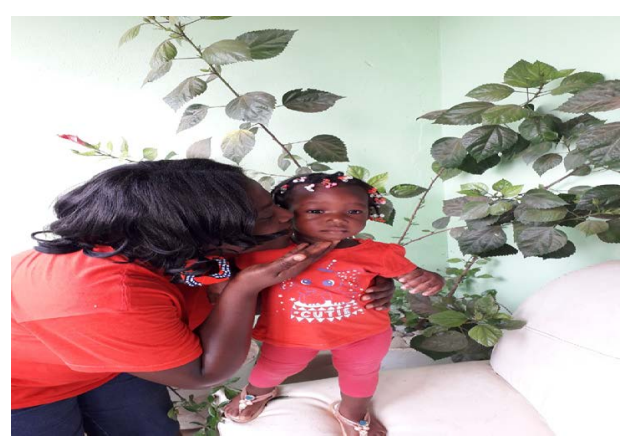

Figure 5. Picture of cheek kiss.

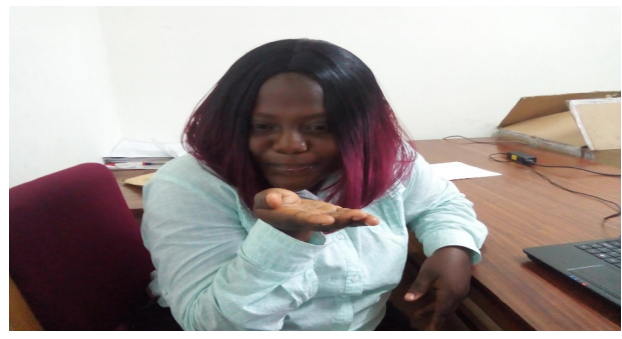

Figure 6. Picture of an angel kiss.

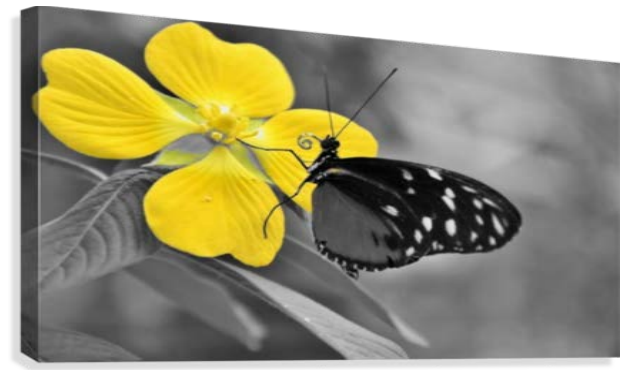

Figure 7. Picture of butterfly kiss. 


\section{Meaning of Butterfly Kissing}

Sometimes, Butterflies do give humans kiss too that is why we have the name butterflies kiss.

In general, Butterflies kiss expresses affection and admiration to the receiver.

In June, that is when a lot of Butterflies get into the environment. These butterflies sucks the nectar's of flowers, hence the name butterfly kiss (Figure 8).

Meaning of Kiss by an Embrace

When both bodies are in close contact, this is an expression of strong surrender and affection and surrender. It ensures that both partners or significant other are willing to give in to one another on both a sexual level and sensual level (Figure 9).

Meaning of Forehead Kissing

A forehead kiss is another form of a social kissing gesture which indicates comforting someone.

And moreover it indicates friendship to someone.

When a girl kisses a man or a guy forehead it means she admires and loves you dearly.

A forehead kiss is a sign of and affection and adoration (Figure 10).

Meaning of Neck Kiss

Another name for a Neck Kiss is also call collarbone Kiss.

If someone gives you a neck kiss indicates a seductive nature which has a feeling of strong intimacy.

Neck kiss on the other hand shows a passion for a certain degree of strong intimacy in the intension of the giver (Figure 11).

Meaning of a Lip Kiss

Lip Kiss or kiss on the Lips shows a lot of passion from the giver, it may mean "I want to date you" or "I love you" (Apr 22, 2011).

If the action is carried out very quickly, by just touching one another's lips, it may simply mean friendship.

This is implies that it is very necessary to know the intensity of the kiss which is an important contributing factor in interpreting its intention (Figure 12).

Meaning of Eskimo Kiss

A kiss on the nose or Nose rub is alternative names for an Eskimo kiss and it is extremely sweet.

All because it can trigger in sparking instant flames of love or it ignites romance.

Is the act of pressing the tip of one's nose against another's nose which is normally interpreted as a form of friendly greeting gesture in various cultures.

It also shows that the significant other is the main the object of interest and committed affection (Figure 13).

Meaning of Kiss on the Ear

Kiss on the ears is interpreted as a very strong power and passionate sexual intention. 


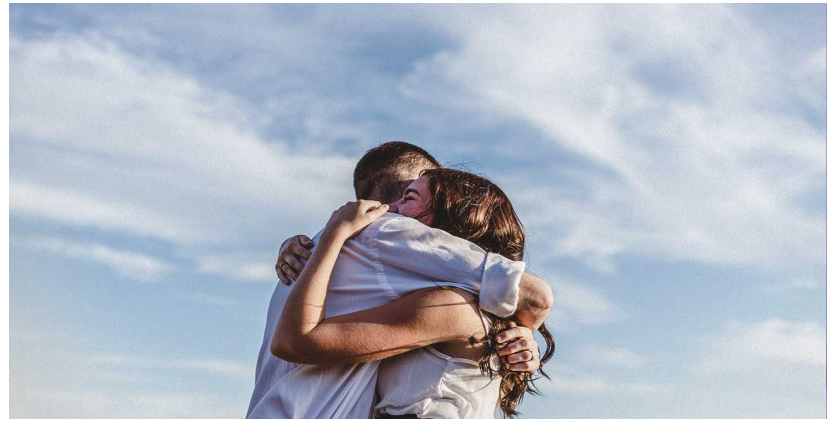

Figure 8. Kiss by an embrace.

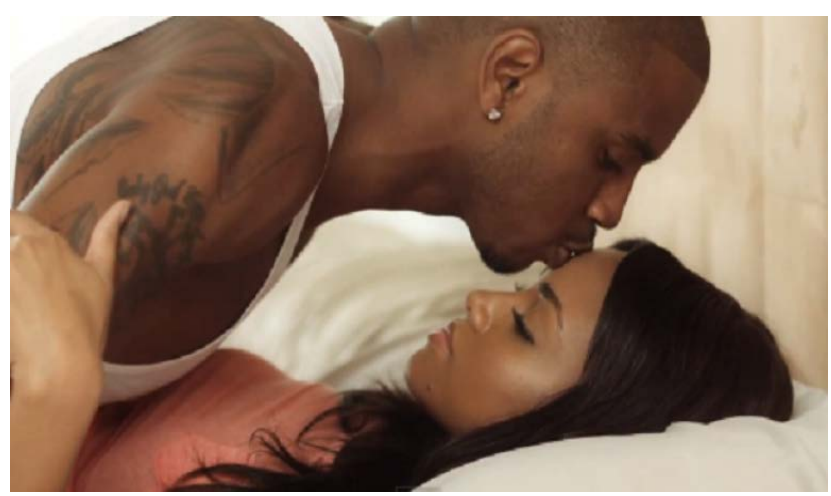

Figure 9. Fore head kiss.

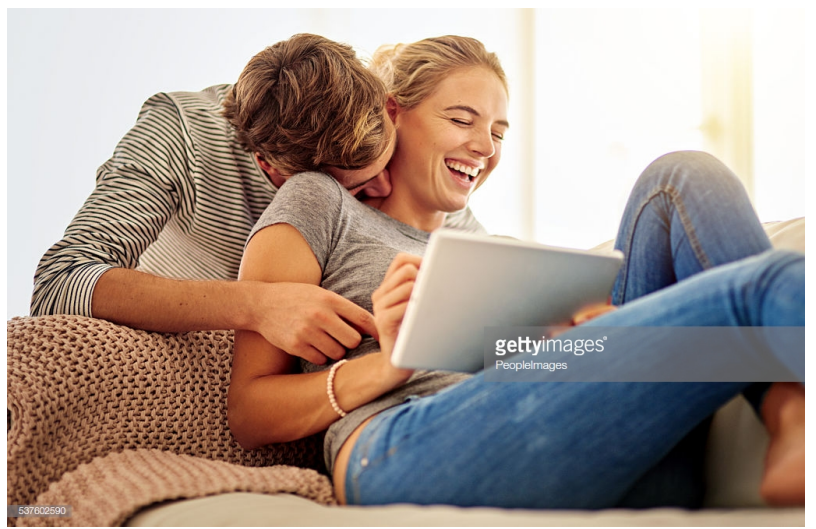

Figure 10. Picture of neck kiss.

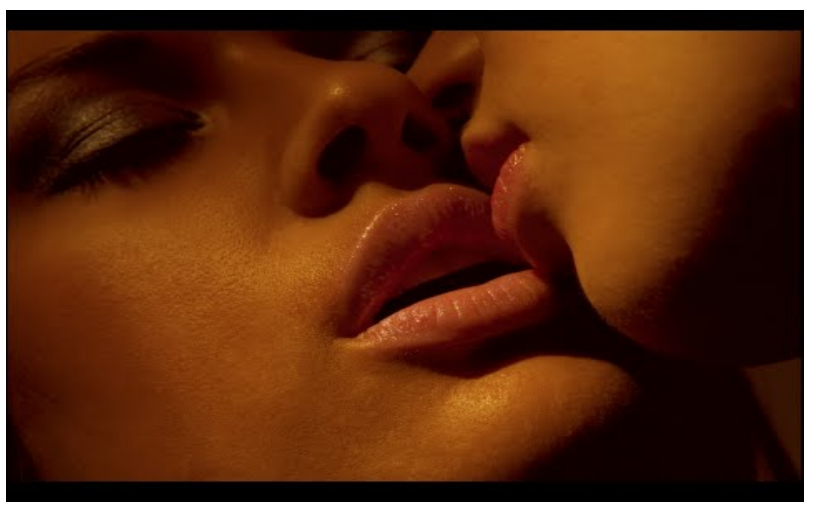

Figure 11. Picture of lip kiss. 


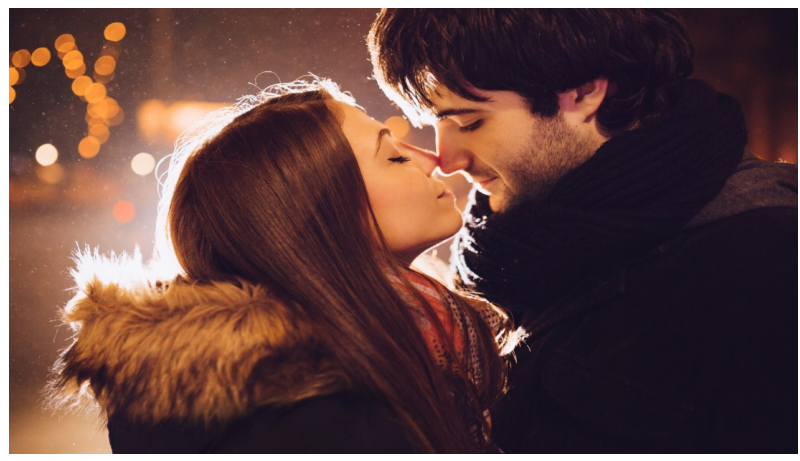

Figure 12. Picture of Eskimo kissing.

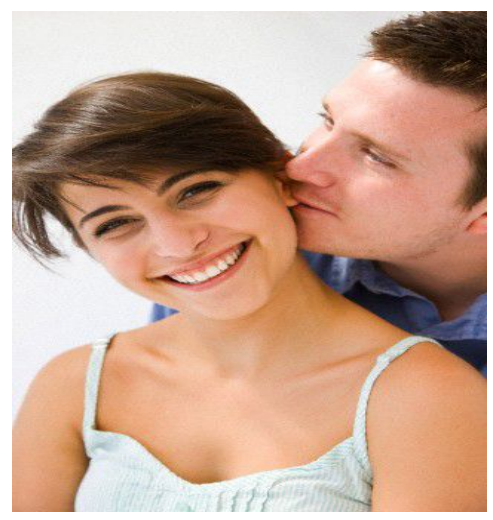

Figure 13. Picture of kiss on the ear.

Initially, it might not be taken too seriously, but depending on the intensity with which the kiss is given it may be interpreted with some romance and erotic evidence.

Which may start with mischief and a lot of foreplay?

\section{Health Effects on Kissing}

During kissing a lot of bacteria and pathogens are transferred from one person to other theses are:

Pathogenic Streptococci.

Syphilitic Spirochetes.

Epstein bar Virus.

Upper Respiratory Infective virus.

Herpes Simplex Virus.

Principles of Epidemiology, 3rd Edition, Oct 9, 2018 (Figure 14).

Effect of Pathogenic Streptococci

If someone is having pathogenic streptococci and he or she kisses his or her significant other, there is a tendency that these pathogens will be transferred to the other person during kissing. The best way out is to abstain from kissing when one is suffering or having these pathogens (Figure 15).

Effect of Drug-Resistant Tuberclosis in kissing

Tuberclosis is a contagious disease so to prevent someone from contacting 
this tuberculosis, it is best advisable to abstain from kissing someone who is having tuberculosis (Figure 16).

Effect of Upper Respiratory Infective Virus

It can be contacted with infected people, especially through kissing and sex.

Upper respiratory tract infections (URTI) are illnesses caused by an acute infection.

This infection is viral in nature.

Which involves the upper respiratory tract including the larynx, pharynx, sinuses and nose (Figure 17)?

Epstein-Barr virus (EBV) is also known as kissing disease, mono and glandular fever.

This infection is also viral in nature, the type of infection it causes is known as infectious mononucleosis.

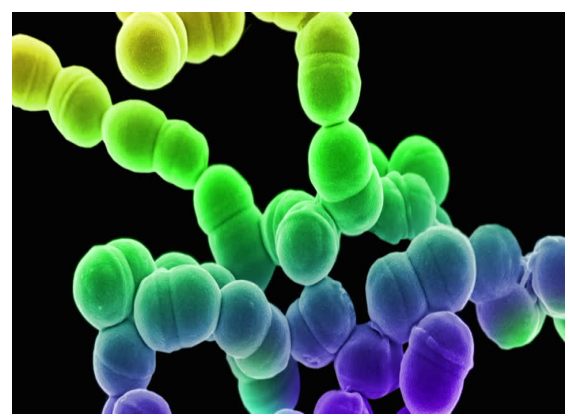

Figure 14. Picture of pathogenic streptococci.

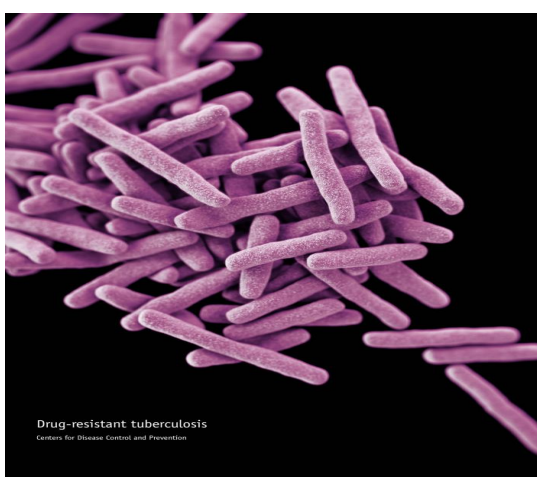

Figure 15. Picture of drug-resistant tuberculosis.

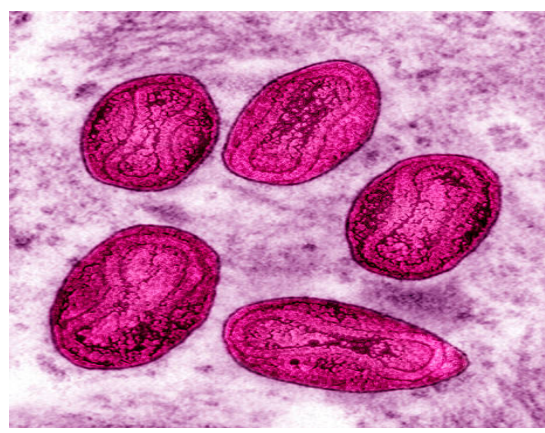

Figure 16. Picture of upper respiratory infective virus. 


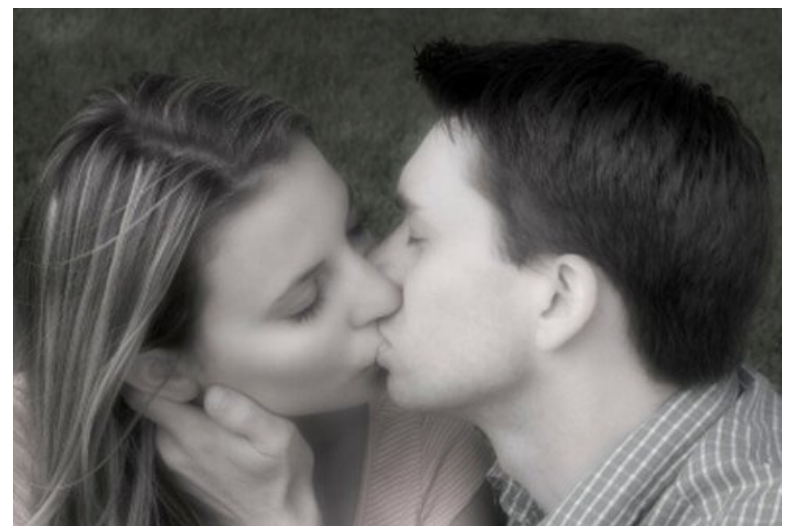

Figure 17. Picture of partners contacting mono disease through kissing.

Symptoms of mononucleosis include sore throat, fever, swollen lymph nodes and fatigue. There is no treatment for mono, but supportive care which involves drinking of plenty water and more especially drinking plenty of fluids. The illness resolves without treatment.

HHV -4, it can be view by electronic microscopy, viral diameter $200 \mathrm{~nm}$.

\section{Conclusions}

The average age for a first kiss should be experienced between 12 and 14 years. Tongue kissing should be also acceptable at that age. Parent kissing their baby is normal [6]. But at the same time, it is best to safeguard the baby from hazardous infections. Don't allow anyone to kiss your baby until he or she is six weeks old [7]. Guys enjoy kissing triangle that is you kiss the lips, then the neck and back to the lips. Kissing your baby is an example of love and affection [8], even babies understand this (July 26, 2015). One of the key points is not let anyone kiss the baby on his or her mouth during the first three (3) months (May 29, 2018), because of the immune system of the baby. To improve kissing, spice up your kiss by starting slow and then move to a more passionate kiss.

In addition, your cholesterol improves, this implies that kissing can improve your overall blood lipid level. Research shows that in a study in 2009 edition of the Western Journal of Communication, researchers found out that romantic kissing can actually decrease your serum cholesterol and increase overall relationship satisfaction for couples [9]. Furthermore, your saliva is designed to help you access potential mates. Researchers at Oxford University have found out that kissing is actually designed to help you access a potential mate. All your brain happy chemicals are released during kissing. Naturally, your pupils dilate when you kiss and your eyes are closed, it makes us susceptible to light sensitivity says Marie Clair.

\section{Acknowledgements}

The authors wished to acknowledge the management of Radiation Protection Institute of Ghana Atomic Energy Commission for using their facilities for con- 
ducting this research.

\section{Conflicts of Interest}

The authors duly agreed that, there is no conflict of interest as far as the publication of this research work is concerned.

\section{References}

[1] Audio Booking Matters: The Chemistry of Attachment. http://www.babyreference.com/bonding

[2] BrainMD Life (2016) 4 Ways to Boost Your Serotonin. BrainMD Life Amen Clinic, $5-6$.

[3] Elhomsy, G., Staros, E.B., et al. (2014) Dopamine. Publishers Medscape. 4-7.

[4] McIntosh, J. and Wilson, D.R. (2018) What Is Serotonin and What Does It Do? Elsevier, Amsterdam, 2-4.

[5] Levy-Gigi, K.S. (2011) Social Effects of Oxytocin in Humans: Context and Person Matter. Medscape Journal, 468-474.

[6] Linda Folden Palmer, D.C. (2002) Neurophysiology of Philematology and Some Infectious Disease. Attachment Parenting International, 5, 13.

[7] Linda Folden Palmer, D.C. (2015) Baby Matter Revised 3rd Edition: What Your Doctor May Not Tell You about Caring for Your Baby. Baby Reference, 376. https://www.amazon.com/baby-matters-revised-3 ${ }^{\text {rd }}$-Doctor/dp/0975317040

[8] Linda Folden Palmer, D.C. (2013). Bonding Matters: The Chemistry of Attachment. Audio Booking, 6-8.

[9] Handlin, L., Peterson, M., et al. (2011) Self-Soothing Behaviours with Particular Reference Release Induced by Non-Noxious Sensory Stimulation. Elsevier, Amsterdam, 2-4. 